\title{
EFFECT OF HIGH HYDROSTATIC PRESSURE TREATMENTS ON VOLATILES OF BERRY PURÉES
}

\author{
V. FARKas, I. Dalmadi* and Cs. Balla \\ Department of Refrigeration and Livestock Products' Technology, Faculty of Food Science, \\ Corvinus University of Budapest, H-1118 Budapest, Ménesi út 45. Hungary
}

(Received: 9 April 2014; accepted: 2 August 2014)

\begin{abstract}
High hydrostatic pressure (HHP) technology, as a promising alternative of thermal-treatment and chemical preservatives, can be used to produce minimally processed foods. It has the advantage of affecting only non-covalent bonds of macromolecules in foods, and thus preserves nutritional components, taste, and flavour exceptionally well. However, HHP also influences enzymatic reactions of food. Although some of these changes are often beneficial, monitoring the potential effects of high pressure treatments - especially in the field of product and technology development - is essential. The aim of this study was to point out some parameters of high hydrostatic pressure technique (pressure, temperature, build-up time, holding time, number of cycles) that can substantially impact the sensory properties of treated products.
\end{abstract}

Keywords: HHP, berry fruits, electronic nose, sensory analysis

High hydrostatic pressure technology (HHP), as a non-thermal preserving technique capable of inactivating or eliminating pathogenic and food spoilage microorganisms while retaining the valuable components of foods, has the potential to serve the needs of food-quality and food-safety simultaneously (AwUAH et al., 2007).

HHP dates back over a century to the research of Bert HoLmEs Hite (1899) - who performed experiments with a variety of foods at elevated pressures -, albeit the technology seemed to be unremarkable until the end of the 1960s, when systematic researches started to explore its effects on microorganisms. Over the last 15-20 years, significant advances took place in the technology, mainly because high pressure equipments have become commercially available (PATTERSON et al., 2007). Nowadays, HHP technique inspires dozens of manufacturers to produce innovative, natural-looking, fresh-like foods that satisfy consumers' need (OEY et al., 2008).

When using HHP treatment, an elevated pressure is applied in an instantaneous way throughout the product, subjecting foods to $100-1000 \mathrm{MPa}$ under water or a special fluid as pressure transmitting medium (CAO et al., 2012). Due to the instantaneously transmitted pressure, processing time and conditions are independent of the volume and shape of the treated sample (NorTON \& Sun, 2008; KARIM, 2011).

Beside the inactivation of microorganisms, there are some further effects of pressure on foods. Without the claim of completeness, these are related to enzyme activation or inactivation, protein denaturation and modification, gel formation, not mentioning the changes in the properties of carbohydrates and fats. Although it is generally assumed that the flavour of foods is not impaired by high pressure - since the structure of small volatile compounds is not affected -, HHP processing can induce some enzymatic and chemical

\footnotetext{
* To whom correspondence should be addressed.

Phone: +36-1-482-6065; fax: +36-1-482-6321; e-mail: istvan.dalmadi@uni-corvinus.hu
} 
reactions that finally cause changes in flavour, too. To draw proper conclusions, there is an unequivocal need to integrate objective measurement tools into the generally non-objective sensory ways. Accordingly, it is useful and scientifically justified to apply "artificial sensory tools" when analysing the objective attributes of treated samples.

Electronic nose offers a fast and non-destructive way to sense aroma, so it can be prosperously used to identify the numerous volatile compounds of foods. However, when examining samples with electronic nose, a complex pattern is created without the possibility of defining the aroma components individually. Nowadays, beside the challenges in food authenticity assessment, food quality control, and shelf-life investigation, "e-nose" can be also applied to evaluate food freshness and to reveal changes caused by some preservation techniques (Wilson \& BAiETTO, 2009).

The aim of this study was to determine some parameters of high hydrostatic pressure treatment that can significantly modify the volatiles of berry purées.

\section{Materials and methods}

\subsection{Samples}

Strawberry and raspberry purées were produced with a Robot-Coupe C80 type automatic sieve (Robot-Coupe Ltd., Montceau-les-Mines, France) and used as raw samples, which had been portioned into small polyethylene pouches and heat-sealed airtightly. Plastic pouches were frosted with a Nortech QCF 103 blast chiller (Normann Srl., Orsago, Italy) and then put under frozen storage at $-24{ }^{\circ} \mathrm{C}$.

\subsection{HHP treatments}

Following thawing, HHP treatments were carried out in a Resato FPU-100-2000 HHP equipment (Resato Int. B.V., Roden, Netherlands) that contained a pressurizing (1600 $\mathrm{mm} \times$ $2200 \mathrm{~mm} \times 830 \mathrm{~mm})$ and a control $(1300 \mathrm{~mm} \times 950 \mathrm{~mm} \times 1400 \mathrm{~mm})$ unit. The capacity of the pressurizing chamber was 2 litres, and a so called Resato PG Fluid served as pressure transmitting medium. Where higher temperatures were used, samples were chilled in icy water just after treatments.

Table 1 summarizes the parameters of each HHP treatment. The "build-up time" column means the interval needed to reach $100 \mathrm{MPa}$ pressure elevation. Values represented in the table were mainly based on the settings of industry-wide applied HHP treatments.

\subsection{Measurements with electronic nose}

Electronic nose measurements were performed with an NST 3320 type instrument (Applied Sensor, Linköping, Sweden), which had a built-in headspace sampler for 12 samples, a detector unit containing 23 different sensors, and a software for collecting and processing the data stem from the sensors. NST 3320 consisted of 10 metal oxide semiconductor field effect transistor (MOSFET) sensors, 12 metal oxide semiconductor (MOS) sensors, and a sensor for the detection of relative humidity. The response of the MOS sensors is measured as the change in resistance between the electrodes as a result of the chemical reactions occurring at the surface of the metal oxide semiconductor, while MOSFET sensors are based on a change in the electrostatic potential. Ambient air was filtered through a silica gel drying column, and a combined moisture/hydrocarbon filter was used as clean reference gas for the sensors. The gas flow rate of the dynamic sampling was set to $50 \mathrm{ml} \mathrm{min}^{-1}$. 
Table 1. Parameters of high hydrostatic pressure treatment

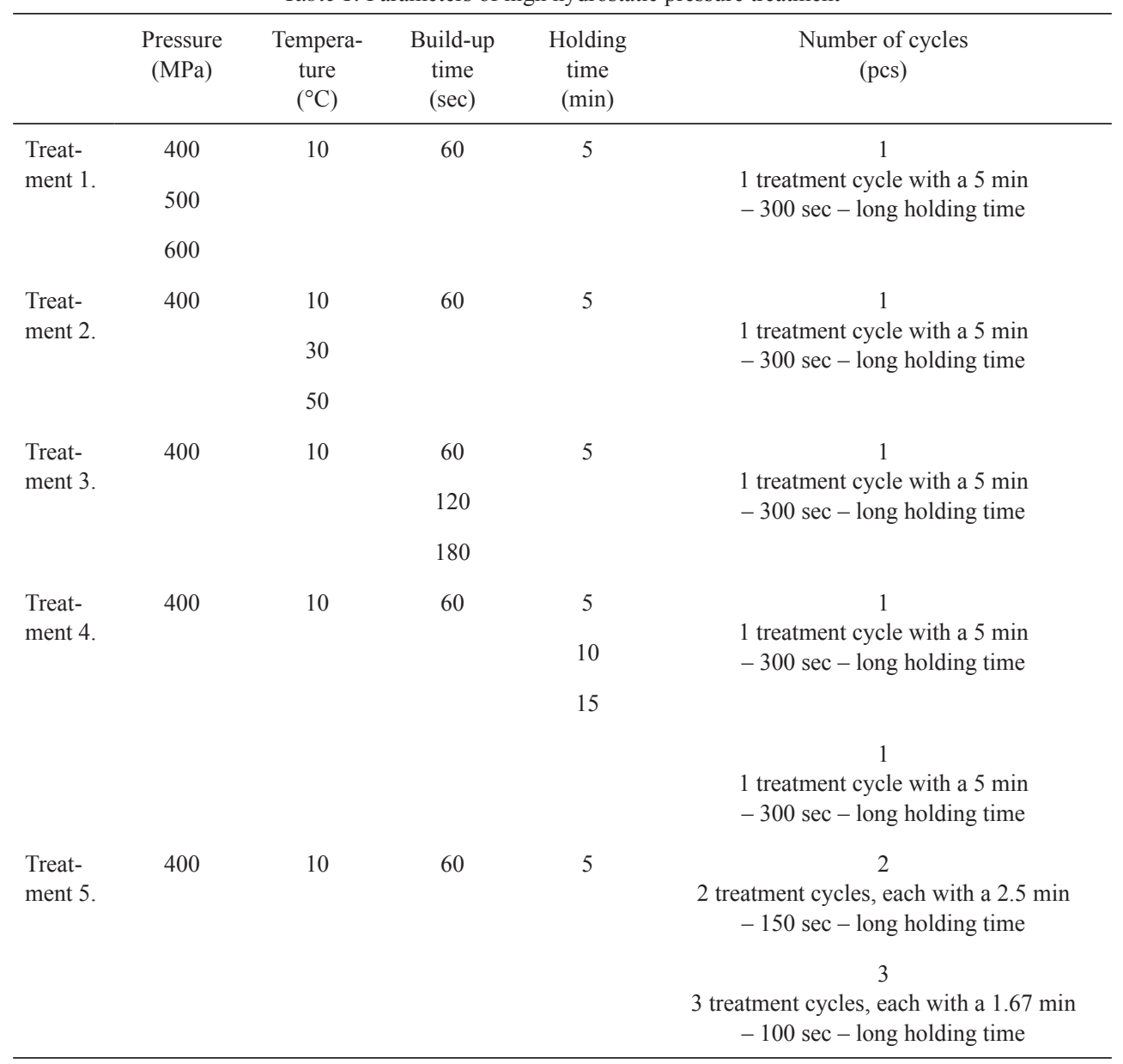

Control (untreated) and HHP-treated purées were put into special glass vials of the electronic nose and were closed by Teflon coated septa. Five grams of sample were put into each vial. Measurements were carried out at stock settings of the e-nose. These settings were framed of a $20{ }^{\circ} \mathrm{C}$ incubation temperature, $20 \mathrm{~min}$ incubation time, $30 \mathrm{sec}$ sampling time, $60 \mathrm{sec}$ flushing time, and a $260 \mathrm{sec}$ long regeneration time. The sequences of the vials were allocated by using a random number generators. The instrument examined each vial in three repetitions. Difference of sensor signals between the baseline and the signal value at the end of the sampling time was used for multivariate statistical analysis as sensor response.

\subsection{Sensory analysis}

Sensory analysis was performed by an untrained sensory panel - with 12 attendants in average - to compare the ability of the e-nose and human perception to differentiate between control and treated berry purées. The panel evaluated the samples subjected to different HHP treatments by using a triangle test (LAWLess \& HeYMANN, 2010), where members were also asked to mark their judgements with a reliability index. 


\subsection{Data analysis}

During the experiments Linear Discriminant Analysis (LDA) (SPSS 20.0 for Windows, Chicago, Illinois, USA) was applied to obtain classification rules for differentiation between berry samples when evaluating electronic nose measurement data.

\section{Results and discussion}

Figure 1 shows the first two typical examples of discriminant analysis results, which are calculated from the sensor responses of the e-nose when different pressure levels were applied for treating raspberry and strawberry purée samples. Based on the distance of different groups, similarity of the classes can be evaluated. Closer groups mean less change in volatiles. As can be seen, control groups separated well from treated samples when raspberry purées were examined, however, the distance of untreated and HHP-treated groups shrank when strawberry samples were put under investigation. These observations were confirmed by the outputs of cross-validation, where a higher classification efficiency could be reached amongst raspberry samples. For example, the control and $600 \mathrm{MPa}$ groups of raspberry purées could be identified $88.9 \%$ and $77.8 \%$ correctly, respectively. At the same time, these numbers were far weaker when examining strawberry samples: $55.6 \%$ and $33.3 \%$.

Nevertheless, the distances between treated samples were smaller than between control and treated ones, and a clear trend could also be realised in the location of treated sample groups. Application of a higher treatment level resulted in a bigger distance from the control group.

\section{A}

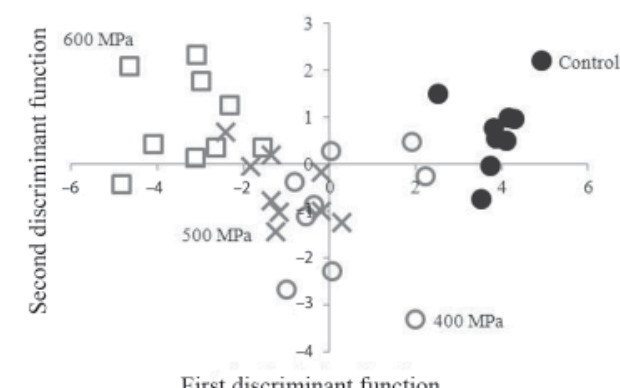

B

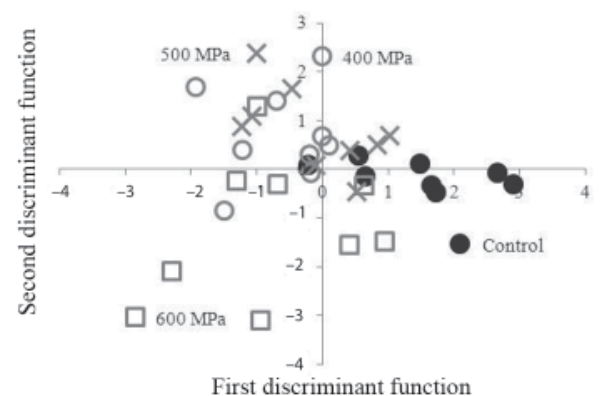

Fig. 1. Discriminant analysis score plots of raspberry (left) and strawberry (right) purées treated with high hydrostatic pressure at different pressure levels - based on the sensor-responses of electronic nose.

(•: Control; o: $400 \mathrm{MPa}$; ×: $500 \mathrm{MPa}$; $: 600 \mathrm{MPa}$ ). A: Raspberry; B: strawberry

As Fig. 2 shows, the different temperatures resulted in a respectable disjunction of control and HHP-treated berry purées. Although the individual samples of the $50{ }^{\circ} \mathrm{C}$ strawberry group demonstrated a considerably bigger deviation, control samples could be separated $100 \%$ correctly from the HHP-treated ones in both cases. 
A

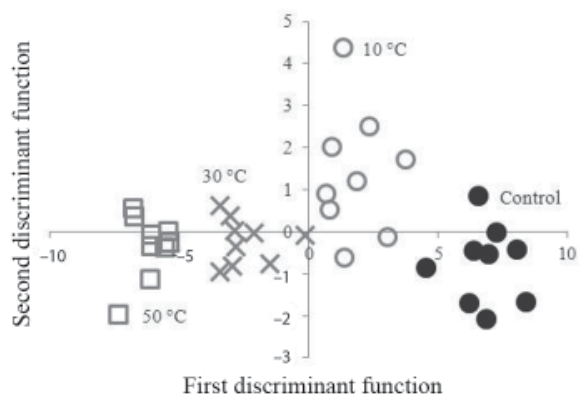

B

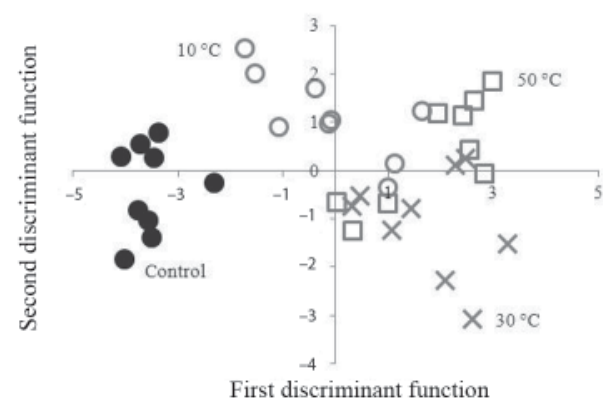

Fig. 2. Discriminant analysis score plots of raspberry (left) and strawberry (right) purées treated with high hydrostatic pressure at different temperatures - based on the sensor-responses of electronic nose.

$\left(\bullet:\right.$ Control; $\left.\circ: 10^{\circ} \mathrm{C} ; \times: 30^{\circ} \mathrm{C} ; \square: 50{ }^{\circ} \mathrm{C}\right)$ ); A: raspberry; B: strawberry

Figure 3 clearly points to the fact that raspberry and strawberry groups showed different tendencies when applying various holding times. Even though control samples could be divided from the treated purée groups in every case, a noticeable overlap appeared between other HHP-treated subgroups. The results of cross-validation verified that the efficiency of classification was weaker among strawberry samples again, not surprisingly.

A

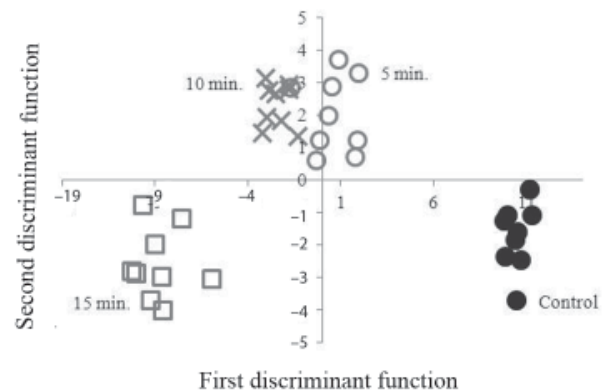

B

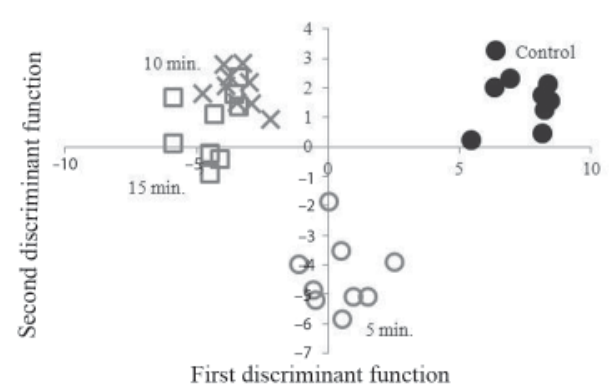

Fig. 3. Discriminant analysis score plots of raspberry purées treated with high hydrostatic pressure at different holding times - based on the sensor-responses of electronic nose.

(•: Control; ०: $5 \mathrm{~min}$; $\times$ : $10 \mathrm{~min}$; $\square: 15 \mathrm{~min})$; ). A: Raspberry; B: strawberry

Table 2 summarizes the main indices related to the efficiency of classification for both berry fruits. Eigenvalues are also represented in the table, which intrinsically compare the deviation measured between and within groups. The bigger the Eigenvalue, the better the groups can be divided from each other. As represented in every Figure above, the greatest difference between groups appeared along the first function, so Table 2 contains the Eigenvalues of the first discriminant function only. Values marked by superscript „a” or „,b” show the cases of the best and the second-best classifications, respectively. 
Table 2. Effects of different HHP parameters on the typical indices of discriminant analysis based on the sensorresponses of the electronic nose

\begin{tabular}{|c|c|c|c|c|c|c|}
\hline \multirow{3}{*}{$\begin{array}{l}\text { Modified parameter of } \\
\text { HHP treatment }\end{array}$} & \multirow{2}{*}{\multicolumn{2}{|c|}{$\begin{array}{l}\text { Eigenvalue of the first } \\
\text { discriminant function }\end{array}$}} & \multicolumn{4}{|c|}{ Efficiency of classification (\%) } \\
\hline & & & \multicolumn{2}{|c|}{ Original model } & \multicolumn{2}{|c|}{ Cross-validated } \\
\hline & Raspberry & Strawberry & Raspberry & Strawberry & Raspberry & Strawberry \\
\hline Pressure & 7.554 & 0.922 & 88.9 & 66.7 & 58.3 & 33.3 \\
\hline Temperature & 26.32 & $5.38^{b}$ & $100^{\mathrm{a}}$ & $80.6^{\mathrm{b}}$ & $86.1^{\mathrm{a}}$ & $63.9^{\mathrm{b}}$ \\
\hline Build-up time & 28.957 & 3.302 & $97.2^{b}$ & 77.8 & 52.8 & 38.9 \\
\hline Holding time & $54.109^{b}$ & $24.221^{\mathrm{a}}$ & $97.2^{b}$ & $100^{\mathrm{a}}$ & $86.1^{\mathrm{a}}$ & $72.2^{\mathrm{a}}$ \\
\hline Number of cycles & $55.256^{\mathrm{a}}$ & 1.445 & 94.4 & 69.4 & $75^{b}$ & 41.7 \\
\hline
\end{tabular}

Superscript "a" and "b" mean the highest and the second-highest values related to the best and the second-best classification

Table 2 demonstrates that different holding times had the greatest effects on the discrimination of the groups, and temperature had the second greatest. It can be seen that different pressures had minor effects regarding the discrimination of groups.

Results of the sensory analysis (Table 3) showed that attendants were not able to separate the control group from the treated samples in general. Even where correct answers were given - based on the marked reliability indexes -, choices could not be attributed to solid considerations. Only the raspberry purées treated with the highest temperature (marked by grey) proved to be significantly different from other samples.

Table 3. Results of triangle tests when samples treated with different parameters of HHP were put under sensory analysis

\begin{tabular}{|c|c|c|c|c|c|c|c|c|c|}
\hline \multirow{2}{*}{$\begin{array}{l}\text { Modified } \\
\text { param- } \\
\text { eter of } \\
\text { HHP } \\
\text { treatment }\end{array}$} & \multirow[b]{2}{*}{$\begin{array}{l}\text { Deter- } \\
\text { mined } \\
\text { levels } \\
\text { (low- } \\
\text { medium- } \\
\text { high) }\end{array}$} & \multicolumn{6}{|c|}{ Number of correct answers } & \multirow{2}{*}{$\begin{array}{c}\text { Number } \\
\text { of } \\
\text { panellists }\end{array}$} & \multirow[b]{2}{*}{$\begin{array}{c}\text { Minimum } \\
\text { number } \\
\text { of correct } \\
\text { judgments } \\
\text { to establish } \\
\text { significance at } \\
\text { probability } \\
\text { level of } 5 \%\end{array}$} \\
\hline & & low & $\begin{array}{c}\text { Raspberry } \\
\text { medium }\end{array}$ & high & low & $\begin{array}{c}\text { Strawberry } \\
\text { medium }\end{array}$ & high & & \\
\hline $\begin{array}{l}\text { Pressure } \\
(\mathrm{MPa})\end{array}$ & $\begin{array}{l}400-500- \\
600\end{array}$ & 3 & 5 & 4 & 2 & 3 & 1 & 11 & 7 \\
\hline $\begin{array}{l}\text { Tempera- } \\
\text { ture } \\
\left({ }^{\circ} \mathrm{C}\right)\end{array}$ & $10-30-50$ & 4 & 3 & 7 & 5 & 5 & 3 & 10 & 7 \\
\hline $\begin{array}{l}\text { Build-up } \\
\text { time } \\
(\mathrm{sec} / 100 \\
\mathrm{MPa})\end{array}$ & $\begin{array}{l}60-120- \\
180\end{array}$ & 3 & 3 & 3 & 6 & 6 & 5 & 13 & 8 \\
\hline $\begin{array}{l}\text { Holding } \\
\text { time } \\
(\mathrm{min})\end{array}$ & $5-10-15$ & 3 & 5 & 4 & 2 & 6 & 2 & 17 & 10 \\
\hline $\begin{array}{l}\text { Number } \\
\text { of cycles } \\
\text { (pcs) }\end{array}$ & $1-2-3$ & 1 & 2 & 3 & 4 & 3 & 3 & 10 & 7 \\
\hline
\end{tabular}




\section{Conclusions}

According to our study, the sensors of the electronic nose were capable of distinguishing the subgroups of HHP-treated samples from the untreated ones.

Results confirmed that the potential effects of high pressure treatment - combined with mild heat - on the volatiles of berry purées cannot be certainly prognosticated. For example, when samples were subjected to different pressures, treated groups of raspberry purées definitely separated from the control samples. At the same time, the difference diminished between strawberry groups where bigger overlaps appeared and the deviation of the individual samples within groups also increased. Former studies came to similar results, when heat- and HHP-treated raspberry, strawberry, and blackcurrant purées were examined with e-nose, just after treatments as well as during two- and four-week long storage times (DALMADI et al., 2007; DALMADI, 2009).

Comparing the effects of the parameters, it could be stated that holding time and temperature principally affected the volatile compounds, while the impact of different pressures was not so remarkable.

Furthermore, experiments confirmed that the human sensory panel could not differentiate between raw (control) and treated samples. Thus, it could be conceived that e-nose proved to be a better tool when classifying control and HHP-treated berry purées.

The work of Valér Farkas has been supported by the European Union and Hungary in the framework of the TÁMOP 4.2.4.A/1-11-1-2012-0001 "National Excellence Program - National Program for elaboration and run of the system for personal support for Hungarian students and researchers", however, authors also acknowledge the support of the funding TÁMOP 4.2.1/B/09/1/KMR/-2010-0005 program of the National Development Agency.

\section{References}

Awuah, G.B., Ramaswamy, H.S. \& Economides, A. (2007): Thermal processing and quality: Principles and overview. Chem. Eng. Process., 46, 584-602.

CaO, X., Bi, X., Huang, W., Wu, J., Hu, X. \& Liao, X. (2012): Changes of quality of high hydrostatic pressure processed cloudy and clear strawberry juices during storage. Innov. Food Sci. Emerg., 16, 181-190.

Dalmadi, I. (2009): Development of quality characteristics of berries pasteurized by heat treatment or high hydrostatic pressure as a function of storage temperature. PhD Thesis, Corvinus University, Budapest, pp. 63-74.

Dalmadi, I., Polyák-Fehér, K. \& Farkas, J. (2007): Effects of pressure- and thermal-pasteurization on volatiles of some berry fruits. High Pressure Res., 27 (1), 169-172.

Hite, B.H. (1899): The effect of pressure in the preservation of milk - a preliminary report. W. Va Agr. Exp. St. Bull., 58.

KARIM, P.A. (2011): High pressure processing as an alternative food preservation technology and its applications for fruits and vegetables. MSc Report, Kansas State University, Manhattan, Kansas, pp. 1-13.

Lawless, H.T. \& Heymann, H. (2010): Discrimination testing. -in: Sensory evaluation of food: Principles and practices, $2^{\text {nd }}$ ed., Springer, London, UK, pp. 79-100.

Norton, T. \& Sun, D-W. (2008): Recent advances in the use of high pressure as an effective processing technique in the food industry. Food Bioprocess Tech., 1 (1), 2-34.

Oey, I., Lille, M., VAn Loey, A. \& Hendrickx, M. (2008): Effect of high-pressure processing on colour, texture and flavour of fruit- and vegetable-based food products: A review. Trends Food Sci. Tech., 19 (6), 320-328.

Patterson, M.F., Linton, M. \& Doona, C.J. (2007): Introduction to high pressure processing of foods. -in: DoonA, C.J., Dunne, C.P. \& Feenerry, F.E. (Eds) High pressure processing of foods, $1^{\text {st }}$ ed., Blackwell Publishing Professional, Iowa, USA, pp. 1-14.

Wilson, A.D. \& Baietto, M. (2009): Applications and advances in electronic-nose technologies. Sensors, 9, 50995148. 